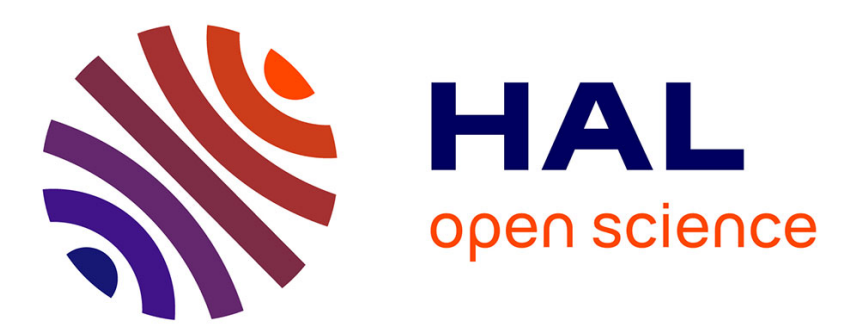

\title{
Anisotropy effects on the tensile and fatigue behaviour of an oxide dispersion strengthened copper alloy
}

Abderrazak Daoud, Jean-Bernard Vogt, Eric Charkaluk, Jérémie Bouquerel, Lin Zhang, Jean-Claude Biasci

\section{To cite this version:}

Abderrazak Daoud, Jean-Bernard Vogt, Eric Charkaluk, Jérémie Bouquerel, Lin Zhang, et al.. Anisotropy effects on the tensile and fatigue behaviour of an oxide dispersion strengthened copper alloy. Materials Science and Engineering: A, 2012, 534, pp.640-648. 10.1016/j.msea.2011.12.021 . hal-00669670

\section{HAL Id: hal-00669670 \\ https://hal.science/hal-00669670}

Submitted on 27 Jul 2021

HAL is a multi-disciplinary open access archive for the deposit and dissemination of scientific research documents, whether they are published or not. The documents may come from teaching and research institutions in France or abroad, or from public or private research centers.
L'archive ouverte pluridisciplinaire HAL, est destinée au dépôt et à la diffusion de documents scientifiques de niveau recherche, publiés ou non, émanant des établissements d'enseignement et de recherche français ou étrangers, des laboratoires publics ou privés. 


\title{
Anisotropy effects on the tensile and fatigue behaviour of an oxide dispersion strengthened copper alloy
}

\author{
Abderrazak Daoud a , Jean-Bernard Vogt ${ }^{\mathrm{a}, *}$, Eric Charkaluk ${ }^{\mathrm{b}}$, Jérémie Bouquerel ${ }^{\mathrm{a}}$, Lin Zhang ${ }^{\mathrm{c}}$, \\ Jean-Claude Biascic \\ a Université Lille1, Unité Matériaux Et Transformations ENSCL/USTL, UMR CNRS 8207, Bâtiment C6, 59655 Villeneuve d'Ascq Cedex, France \\ ${ }^{\mathrm{b}}$ Ecole Centrale de Lille, Laboratoire de Mécanique de Lille, UMR CNRS 8107, BP 48, 59651 Villeneuve d'Ascq Cedex, France \\ ${ }^{\mathrm{c}}$ European Synchrotron Radiation Facility, 6 rue Jules Horowitz, BP220, 38043 Grenoble Cedex, France
}

\begin{abstract}
In this study, the mechanical behaviour of the GlidCop ${ }^{\circledR}$ AL-15, an oxide dispersion-strengthened (ODS) copper, is investigated. As the extrusion process leads to a morphological and crystallographic texture, specimens are loaded in a parallel or transverse direction to the extrusion direction.

Higher monotonic mechanical strength is observed when the loading axis is parallel to the extrusion direction. Under cyclic loading, the material is more prone to cyclic hardening-softening behaviour and exhibits higher fatigue resistance in the extrusion direction than in the transverse one.
\end{abstract}

\section{Introduction}

GlidCop ${ }^{\circledR}$ AL-15 an oxide dispersion-strengthened (ODS) copper developed to increase significantly the mechanical strength of basic copper especially at high temperature [1-4]. GlidCop ${ }^{\circledR}$ AL-15 is produced by the internal oxidation method $[5,6]$ that consists of:

- Water atomization of $\mathrm{Cu}-\mathrm{Al}$ alloy melted in an electrical furnace; - drying and sieving to collect powder with an average particle size of $100 \mu \mathrm{m}$;

- oxidation in air flow for $60 \mathrm{~min}$ at $900^{\circ} \mathrm{C}$;

- reduction in hydrogen flow for $60 \mathrm{~min}$ at $800^{\circ} \mathrm{C}$.

The reduced powder is poured into a copper can and precompacted at $500 \mathrm{MPa}$. The can is then pre-heated in an argon atmosphere for $60 \mathrm{~min}$ at $900^{\circ} \mathrm{C}$ and extruded $[7,8]$.

Internal oxidation is a diffusion-controlled process, time required for a complete internal oxidation is one of the key parameters of ODS copper production. Depending on the specimen size, this time must be kept as short as possible to avoid a coarsening of the alumina particles which leads to reduction of the strengthening effect [9]. The internal oxidation process is not sufficient for a

\footnotetext{
* Corresponding author. Tel.: +33 3204340 35; fax: +33 320434040

E-mail addresses: jean-bernard.vogt@ensc-lille.fr, jean-bernard.vogt@univ-lille1.fr (J.-B. Vogt).
}

complete densification. The consolidation into fully dense shapes is normally obtained by extrusion and can be completed by cold rolling to produce wire, rod, strip tube or plate products [7]. The internal oxidation process provides a microstructure containing a very uniform distribution of fine aluminium oxide particles aimed at strengthening the ductile copper matrix. The degree of strengthening is a function of the size, shape, spacing, hardness, distribution and coherency of the second-phase particle with the matrix [10]. The fine particles are hard and thermally stable even at temperatures approaching the melting point of the copper matrix. They do not coarsen but become less effective as barriers to the motion of dislocations [11]. The fine dispersion of the aluminium oxide particles in the copper matrix also moderates or prevents recrystallization, and this effect depends on particles of appropriate size and distribution [12].

GlidCop $^{\circledR}$ AL-15 can be used as a potential high conductivity-high strength material, since the electrical and thermal conductivity of the matrix should not be strongly affected by the addition of a small amount of dispersoid particles incoherent with the metallic matrix. ODS copper alloys are usually employed at high temperatures for resistance welding electrodes in the automotive industry, relay blades, lead wires, electrical conductors, synchrotron units heat absorbers and slits where vacuum integrity below $10^{-10}$ torr is required and in nuclear reactors $[5,6]$. ODS copper alloys are used as heat sink material for the diverter, limiter and first-wall plasma-facing components of the International Thermonuclear Experimental Reactor (ITER) 
Table 1

Chemical composition of GlidCop ${ }^{\circledR}$ AL-15.

\begin{tabular}{llllll}
\hline \multicolumn{2}{l}{ Grade designation } & \multicolumn{2}{c}{ Copper } & & \multicolumn{2}{c}{ Aluminium oxide } \\
\hline UNS & SCM & Wt.\% & Vol.\% & Wt.\% & Vol.\% \\
\hline C15715 & AL-15 & 99.7 & 99.3 & 0.3 & 0.7 \\
\hline
\end{tabular}

[7,8,13-15]. They also constitute excellent liners for the hot sections of high-heat-flux engines, such as combustion chambers of rocket engines for launching space payloads [16]. GlidCop-type ODS alloys appear to be the only copper alloys with good strength above $650^{\circ} \mathrm{C}$ [17]. However, it has been reported that the ductility and low cycle fatigue properties of ODS copper alloys are weak at elevated temperatures [17].

Many studies have been carried out on the preparation methods, recrystallization, microstructure, influence of irradiation and tensile properties of GlidCop. The anisotropy of the microstructure is due to the manufacturing process. Limited attention has been paid to the effect of anisotropy on mechanical properties, mainly for tensile and toughness properties [18,19].

The purpose of the present work is to evidence the effect of anisotropy of an extruded rod of GlidCop ${ }^{\circledR}$ AL-15 on monotonic and cyclic behaviour at room temperature and at $300^{\circ} \mathrm{C}$. In the first part, the material and the experimental procedures are described. Then, metallurgical investigations for the characterization of the GlidCop ${ }^{\circledR}$ AL-15 microstructure are reported. Finally, results coming from tensile and reversed fatigue tests are presented, associated to microstructural investigations conducted on the fracture surfaces. These investigations help to explain the origin and the mechanisms of this mechanical anisotropy.

\section{Material and experimental procedures}

For applications that require lower free oxygen contents such as applications in which the material will be exposed under vacuum to elevated temperatures, special low oxygen ("LOX") grade is mandatory.

The material used in the present investigation was a low oxygen grade aluminium oxide $\left(\mathrm{Al}_{2} \mathrm{O}_{3}\right)$ dispersion-strengthened copper alloy (C15715), hereafter referred to by the trade name GlidCop ${ }^{\circledR}$ AL-15. This alloy was purchased in the form of a $13 \mathrm{~cm}$ diameter extruded rod from the manufacturer OMG Americas (formerly SCM Metal Products, Inc., Research Triangle Park, NC, USA).

Table 1 gives the vendor-reported chemical composition and the volume fraction of the particles.

For the metallographic investigation, the material was mechanically polished using progressively finer grades of silicon carbide paper (220-4000) with water as lubricant, then with diamond paste $(3-0.25 \mu \mathrm{m})$ with DP-red form Struers as lubricant and then electro-polished with electrolyte D solution from Struers under a voltage of $24 \mathrm{~V}$. Finally, the microstructure was revealed using

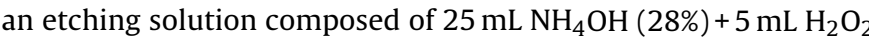
(30\%).

In addition to basic optical microscopy observations, the microstructure was investigated by scanning electron microscopy (SEM). A FEI QUANTA 400 microscope operating at $20 \mathrm{kV}$ and equipped with the electron back scattered diffraction (EBSD) system of Oxford Instruments was used. Diffraction patterns were collected and the data were post processed with the HKL/Oxford Channel 5 software. The microstructure was also imaged by transmission electron microscopy (TEM) using a Tecnai G2 20 TEM operating at $200 \mathrm{kV}$.

For mechanical testing, cylindrical rods were first extracted in two different directions with respect to the extrusion direction: parallel (ED) or transversal (TD) to the extrusion direction. Then,

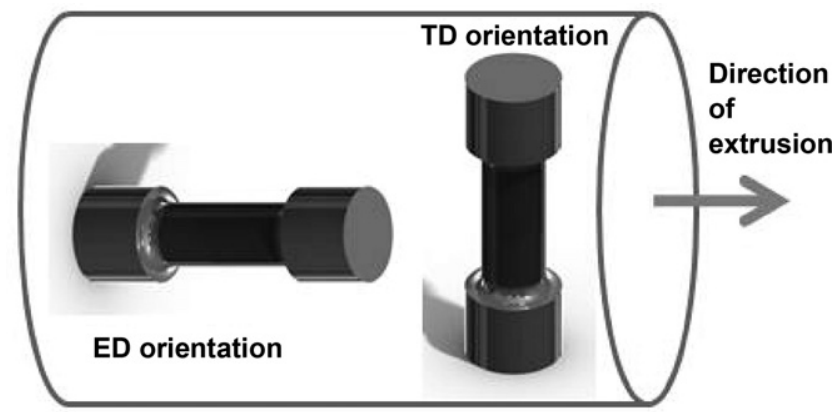

Fig. 1. Orientation of the specimens in respect to the extrusion direction of the rod of GlidCop ${ }^{\circledR}$ AL-15.

tensile and fatigue specimens, $10 \mathrm{~mm}$ in diameter and $15 \mathrm{~mm}$ in gauge length, were machined from the rods (Fig. 1).

Before testing, the specimens were polished using the same procedure as described previously in order to avoid early crack initiation.

Tensile and fatigue tests were carried out on a servo-hydraulic machine. Tensile tests were carried out at room temperature at a constant strain rate of $2 \times 10^{-3} \mathrm{~s}^{-1}$. Low cycle fatigue (LCF) tests were performed at room temperature and at $300^{\circ} \mathrm{C}$ under axial total strain control $\Delta \varepsilon_{\mathrm{t}}=0.6 \%, \Delta \varepsilon_{\mathrm{t}}=0.8 \%$ and $\Delta \varepsilon_{\mathrm{t}}=1 \%$. A fully pushpull mode $\left(R_{\varepsilon}=-1\right)$, a triangular waveform, a constant strain rate of $4 \times 10^{-3} \mathrm{~s}^{-1}$ were employed. The temperature was monitored and measured by a thermocouple in the gauge length of the specimen. The fatigue life $N_{\mathrm{f}}$ was defined as the necessary number of cycles for a $25 \%$ drop in the tensile stress taking as a reference the stabilized hysteresis loop.

\section{Results and analysis}

\subsection{Metallographic characterization and microstructure}

The microstructure of the material, observed on surfaces parallel or perpendicular to the direction of extrusion, is shown in Fig. 2a and $\mathrm{b}$, respectively.

As a consequence of the process, the material exhibited a morphologic texture with grains elongated in the extrusion direction. The grain size of GlidCop ${ }^{\circledR}$ AL-15 ranges between 5 and $15 \mu \mathrm{m}$ in a plane parallel to the extrusion direction and between 0.3 and $0.9 \mu \mathrm{m}$ in a plane perpendicular to the extrusion direction. The statistical distribution obtained by EBSD (Fig. 3) shows that the grain size of GlidCop ${ }^{\circledR}$ AL-15 in a plane perpendicular to the extrusion direction is rather homogeneous with a value of $0.4 \mu \mathrm{m}$ for $75 \%$ of the grains.

Crystallographic texture was determined by indexing EBSD patterns collected on surfaces perpendicular and parallel to the extrusion direction (Fig. 4a and b, respectively). Our first investigation on a surface perpendicular to the extrusion direction showed all the crystallographic orientations. This suggests that the extrusion direction is characterized by the absence of crystallographic texture (Fig. 4a). However, at the grain scale, it was noted that the crystallographic orientations were not randomly distributed. Indeed, the surface appeared as a mosaic of grain packets, with each packet representing an area up to $100 \mu \mathrm{m}^{2}$ and having nearly the same orientation. On a plane parallel to the extrusion direction, the inverse pole figure map (Fig. 4b) revealed a microstructure comprising textured bands. One band contained grains of various orientations but mainly oriented $\langle 111\rangle$ parallel to the extrusion direction, while the other band contained grains possessing only the $\langle 001\rangle$ axis parallel to the extrusion direction. Moreover, the 

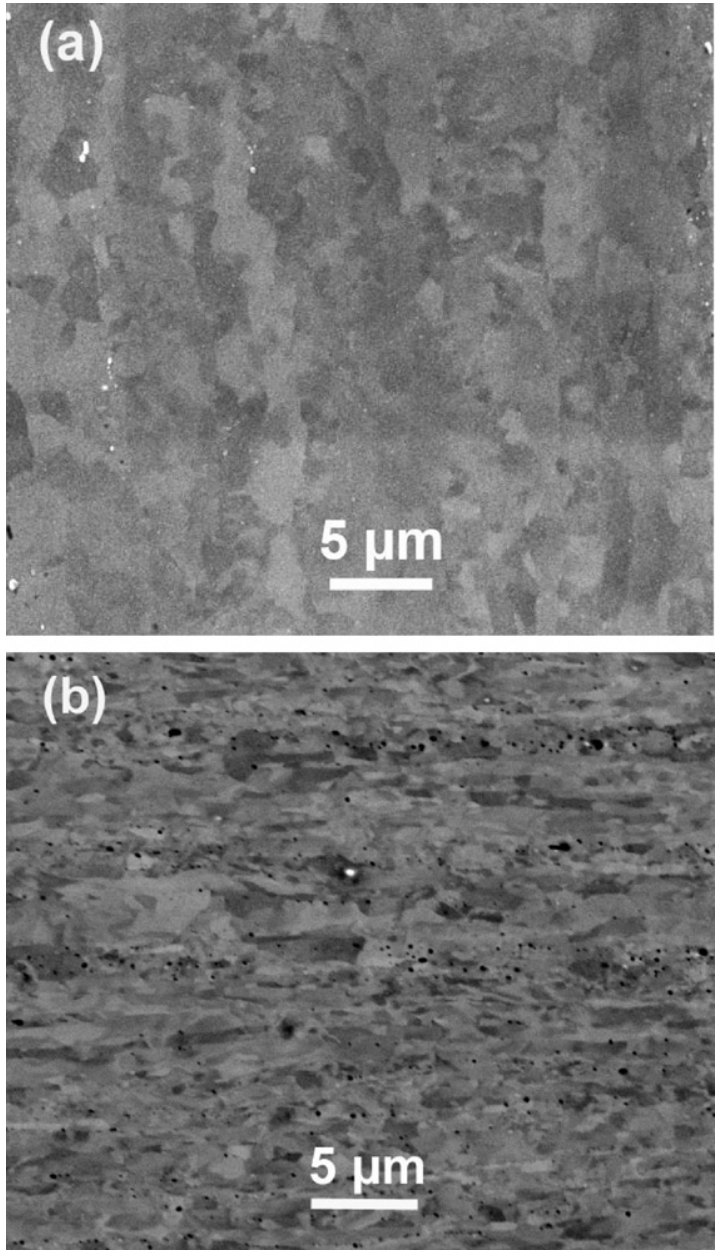

Fig. 2. SEM micrographs of the GlidCop ${ }^{\circledR}$ AL-15: surface parallel to the extrusion direction (a) and perpendicular to the extrusion direction (b).

orientation imaging map pointed out that this particular texture corresponds to a succession of layers up to $20 \mu \mathrm{m}$ thick.

TEM observations revealed that the $\mathrm{Al}_{2} \mathrm{O}_{3}$ particles were uniformly dispersed in the copper matrix (Fig. 5a). These particles

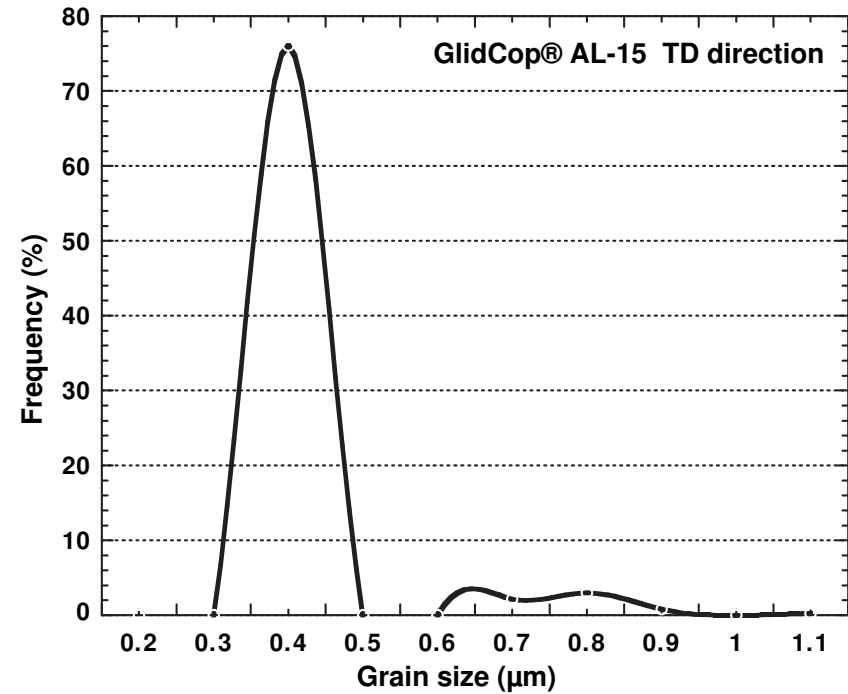

Fig. 3. Grain size distribution in the studied GlidCop ${ }^{\circledR}$ AL-15 in a section perpendicular to the extrusion direction.

impede dislocations that reduce their mobility (Fig. 5b). Although no statistical analysis on particle size was made in the present work, they were in the classic range of 3-12 $\mathrm{nm}$ with an inter-particle spacing of $30-100 \mathrm{~nm}$ and a particle density of $10^{16}-10^{17} \mathrm{~cm}^{-3}$ [20].

\subsection{Monotonic tensile behaviour}

\subsubsection{Mechanical Response}

Monotonic tensile tests were first conducted. The engineering stress-strain curve and true stress-true strain curves of GlidCop ${ }^{\circledR}$ AL-15 are shown in Fig. 6a in a linear scale and (b) in a log-log scale, respectively.

Table 2 summarizes the room temperature tensile properties of GlidCop ${ }^{\circledR}$ AL-15 loaded in both directions. It can be seen that the loading direction produces a large variation in mechanical behaviour. Yield stress (YS), ultimate tensile strength (UTS), elongation to fracture (A) and reduction in area (RA) were lower for the specimen loaded in the transverse direction than for the specimen
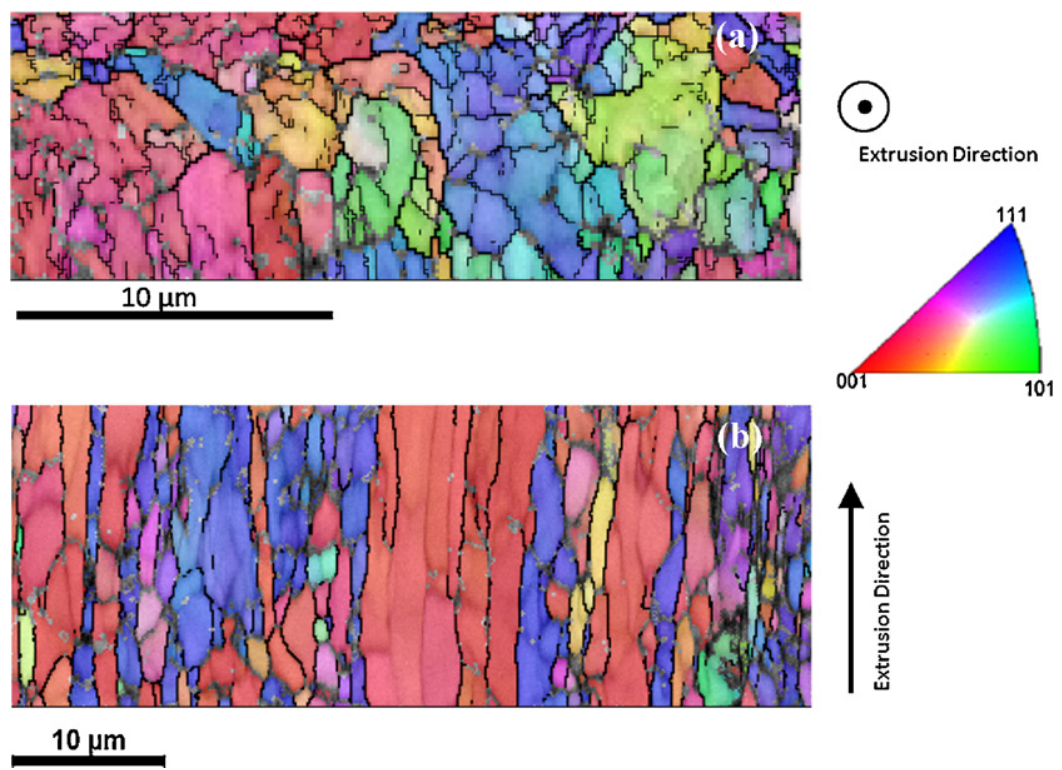

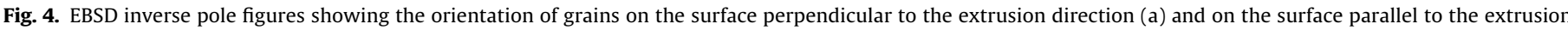
direction (b) of GlidCop ${ }^{\circledR}$ AL-15 rod. 

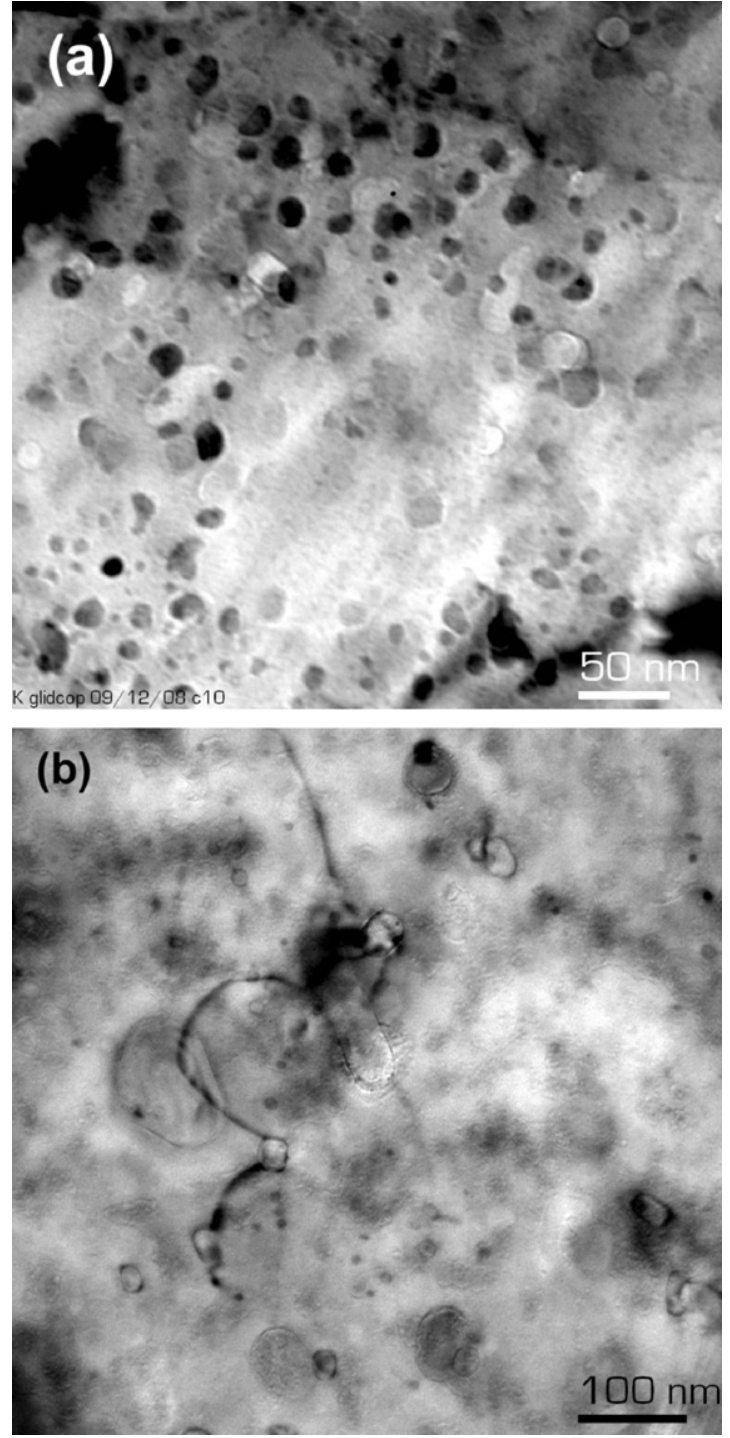

Fig. 5. TEM micrographs showing: (a) fine dispersion of $\mathrm{Al}_{2} \mathrm{O}_{3}$ particles in the copper matrix; and (b) bowing of dislocations impeded by $\mathrm{Al}_{2} \mathrm{O}_{3}$ particles in the studied of GlidCop ${ }^{\circledR}$ AL-15.

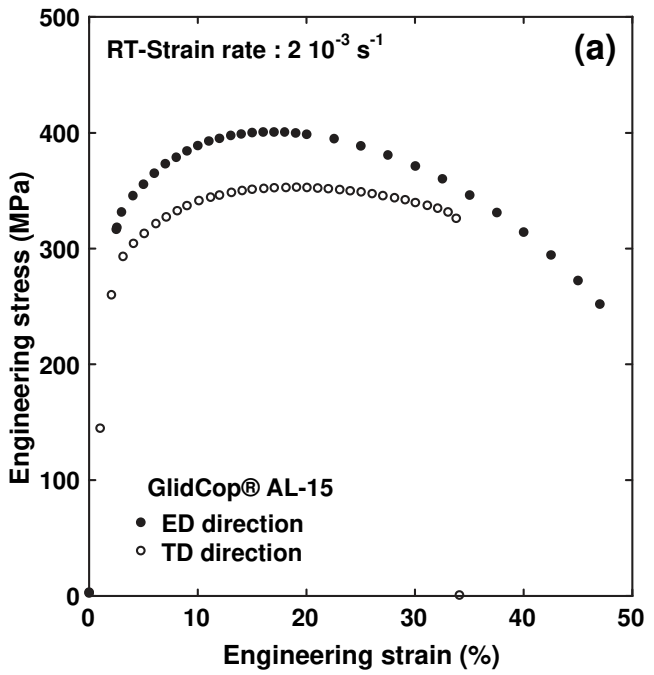

loaded in the extrusion direction. However the opposite was observed for uniform elongation.

The variation of true stress $\left(\sigma_{\mathrm{t}}\right)$ with true plastic strain $\left(\varepsilon_{\mathrm{tp}}\right)$ follows the power law: $\sigma_{\mathrm{t}}=K\left(\varepsilon_{\mathrm{tp}}\right)^{n}$.

The strain hardening exponent $n$ was the same for both directions but the monotonic strength coefficient $K$ decreased from $275 \mathrm{MPa}$ to $241 \mathrm{MPa}$ for the extrusion direction compared to the transverse direction specimens.

The fracture energy, including plastic deformation and crack propagation energies was higher when GlidCop ${ }^{\circledR} \mathrm{AL}-15$ was loaded in the extrusion direction than in the transverse direction. The same conclusion can be drawn concerning the difference between $A$ and $A_{\mathrm{u}}$ values.

Thus, our study shows that GlidCop ${ }^{\circledR}$ AL-15 exhibits its best behaviour when it is loaded in the extrusion direction rather than in the transverse direction, although the properties in the transverse direction remain at a high level with the same properties of work hardenabilty. This is favourable for the extrusion process and it is in agreement with the fracture toughness results of Alexander et al. [18] who found that GlidCop ${ }^{\circledR}$ AL-15 has a higher toughness when the material is loaded in the extrusion direction than in the transverse direction.

\subsubsection{Fracture surface}

Fracture surfaces of specimens deformed in the extrusion and transverse directions at room temperature and at a constant strain rate of $2 \times 10^{-3} \mathrm{~s}^{-1}$ are shown in Fig. 7 .

A substantial macroscopic difference in the fracture aspect was observed between extrusion direction and transverse direction specimens. At low magnification, the fracture surface of the specimen loaded in the transverse direction was rather flat and characterized by a laminated morphology (Fig. 7a). The aligned grain structure parallel to the extrusion direction was the result of the process used in the fabrication of GlidCop ${ }^{\circledR}$ AL-15. At higher magnification, it was noted that the fracture surface contained dimples typical of a ductile fracture (Fig. 7c). This suggests that the cracks are formed by microvoid nucleation and coalescence. The crack growth was influenced by the laminated morphology of the microstructure, which provides a path without changing the mechanism of the fracture.

In contrast, macroscopically, the fracture surface of the specimen loaded in the extrusion direction had a helical shape (Fig. 7b). At higher magnification, the fracture surface was covered by a

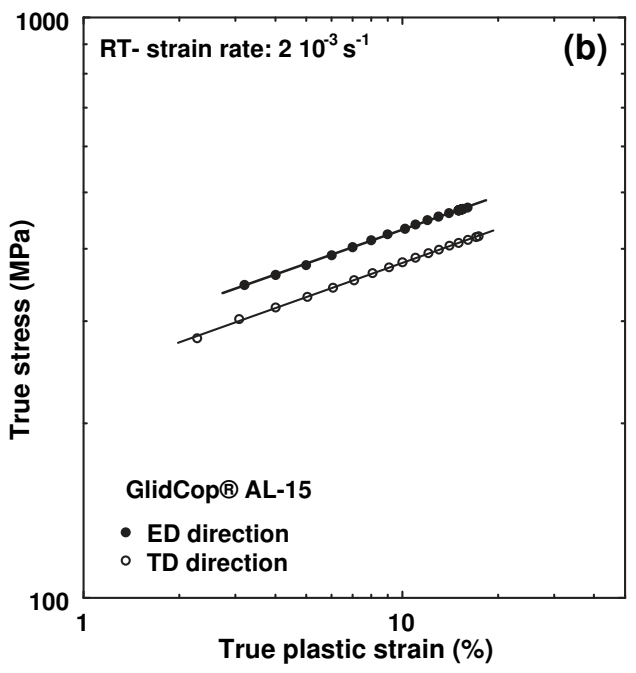

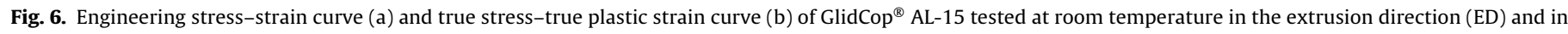
the transverse direction (TD). 
Table 2

Effect of loading orientation on mechanical properties of GlidCop ${ }^{\circledR}$ AL-15 obtained from monotonic tensile tests at room temperature.

\begin{tabular}{|c|c|c|c|c|c|c|c|c|c|}
\hline Orientation & $E(\mathrm{GPa})$ & Y S (MPa) & UTS (MPa) & $A(\%)$ & $A_{\mathrm{u}}(\%)$ & R.A. (\%) & $n$ & $K(\mathrm{MPa})$ & Area under curve $(\mathrm{J})$ \\
\hline Extrusion direction & 100 & 325 & 401 & 47 & 14 & 68.7 & 0.19 & 275 & 127 \\
\hline Transverse direction & 100 & 275 & 352 & 34 & 19 & 36.7 & 0.19 & 241 & 87 \\
\hline
\end{tabular}

uniform distribution of dimples of variable size and depth (Fig. 7d). It is, however, difficult to state whether there is a difference in distribution of microvoids between extrusion and transverse direction specimens because it is hard to localize the area where the crack initiates in the transverse direction specimen.

These results are in agreement with those published by Li et al. in the temperature range from $20^{\circ} \mathrm{C}$ to $300^{\circ} \mathrm{C}$ [21].

\subsection{Low cycle fatigue}

\subsubsection{Cyclic accommodation}

Pure reversed low cycle fatigue tests were then conducted. The evolution of the stress amplitude in terms of cycles $N$ and fatigue life fraction percentage is reported on a logarithmic scale in Fig. 8a and b, respectively, for tests at room temperature and in Fig. 9a and b for tests at $300^{\circ} \mathrm{C}$.

At room temperature, a very slight cyclic hardening was observed when the GlidCop ${ }^{\circledR} \mathrm{AL}-15$ was strained in the transverse direction (Fig. 8a). This hardening appeared more pronounced when cyclic straining was in the extrusion direction. For the highest strain range test $\left(\Delta \varepsilon_{\mathrm{t}}=1 \%\right)$, the increase in stress amplitude was especially high during the first ten cycles and was followed by a weak softening before stabilization (Fig. 8b).

Increasing the test temperature from room temperature to $300{ }^{\circ} \mathrm{C}$ resulted in a decrease of the stress amplitude and promoted cyclic softening (compare Figs. 8a and 9a). Essentially, GlidCop ${ }^{\circledR}$ AL15 remained stable or exhibited a slight softening during the main part of its lifetime (see Figs. 8b and 9b).

\subsubsection{Fatigue resistance}

The hysteresis loop recorded at mid-lifetime $\left(N_{\mathrm{f}} / 2\right)$ was taken as the reference cycle for measurement of stress and deformation values.

The fatigue resistance diagrams, where the total strain amplitude $\left(\Delta \varepsilon_{\mathrm{t}} / 2\right)$ and the plastic strain amplitude $\left(\Delta \varepsilon_{\mathrm{p}} / 2\right)$ are plotted against the number of cycles to failure, are shown in Fig. 10a for tests at room temperature and in Fig. $10 \mathrm{~b}$ for tests at $300^{\circ} \mathrm{C}$.
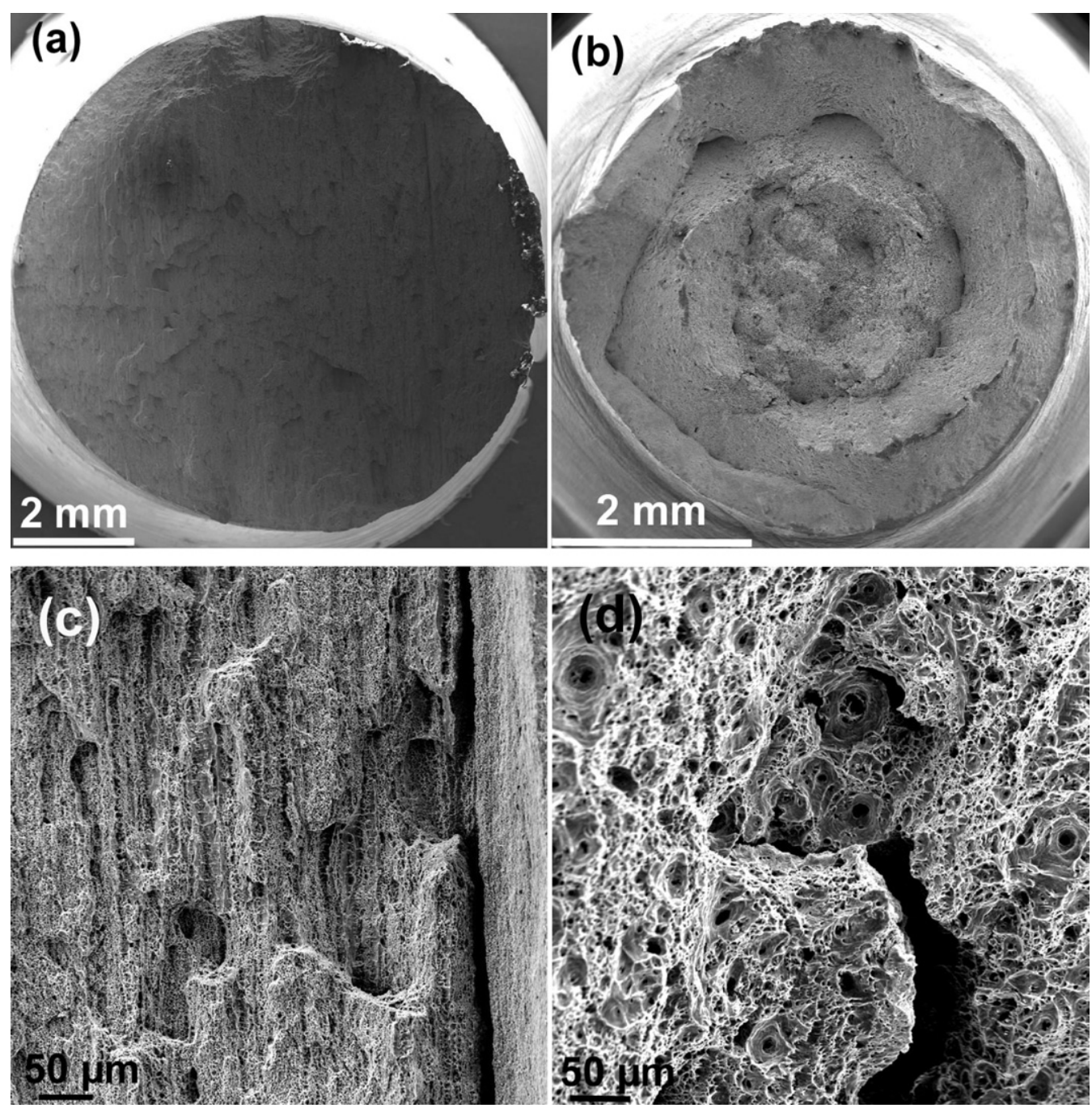

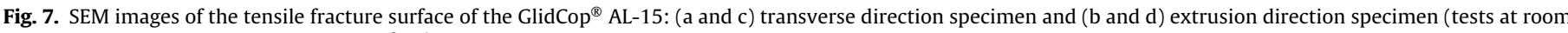
temperature and at a strain rate of $2 \times 10^{-3} \mathrm{~s}^{-1}$ ). 

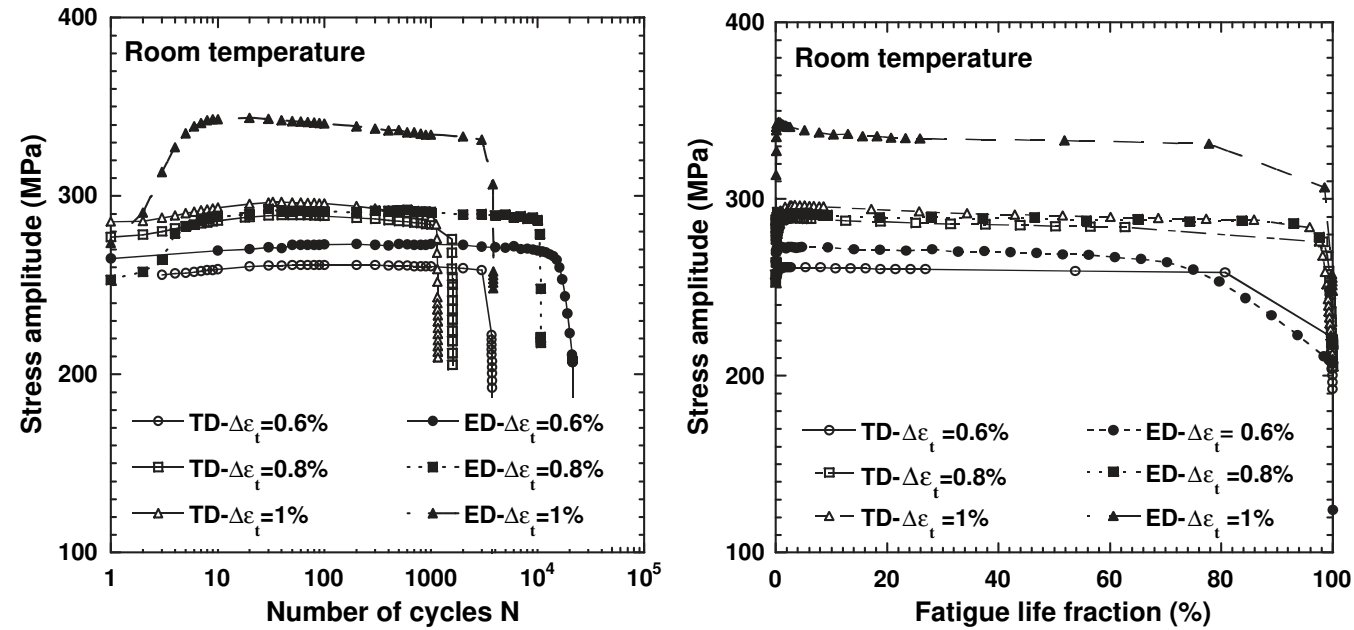

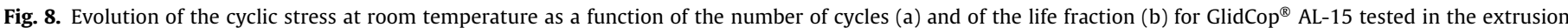
direction (ED) and transverse direction (TD).
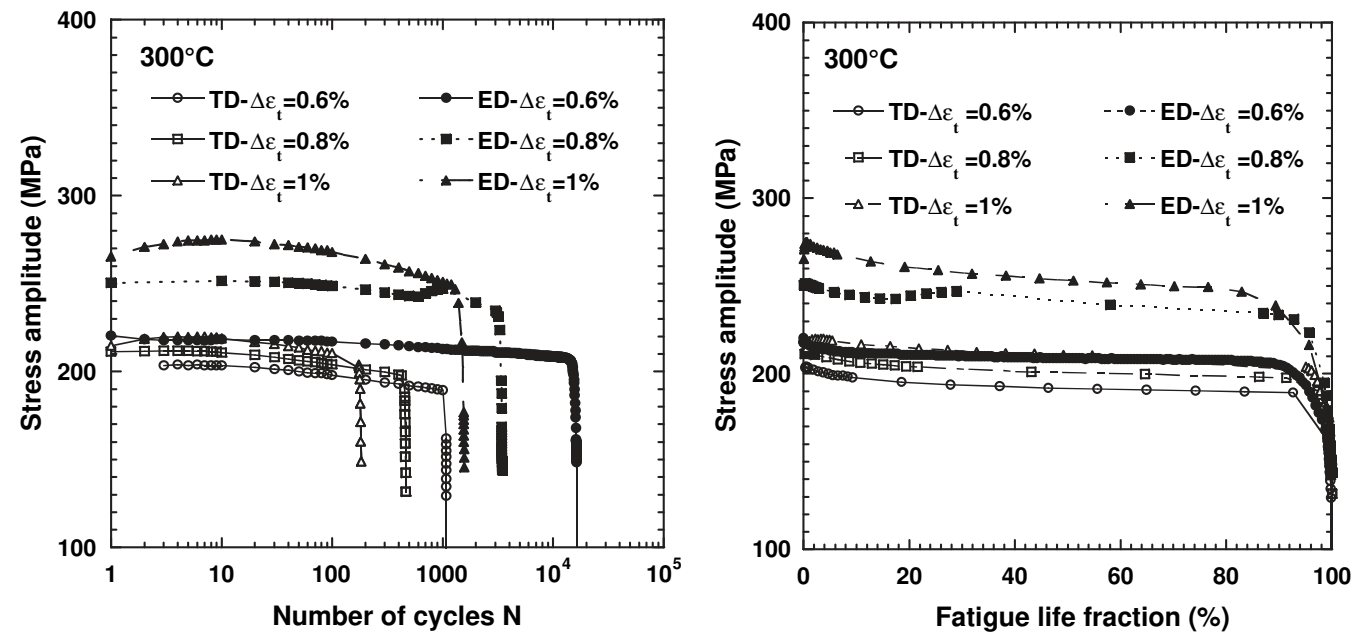

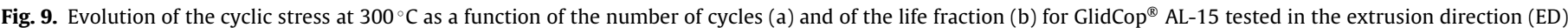
and transverse direction (TD).
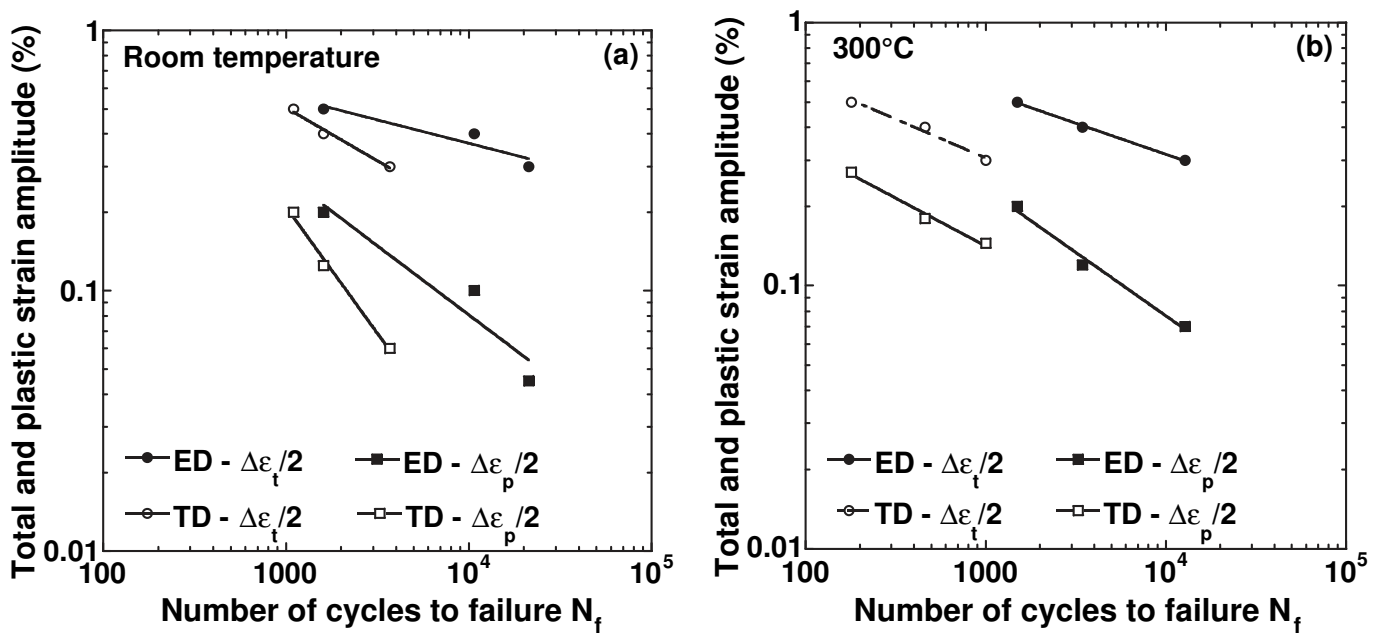

Fig. 10. Fatigue resistance diagrams of GlidCop ${ }^{\circledR}$ AL-15 tested at room temperature (a) and at $300{ }^{\circ} \mathrm{C}(\mathrm{b})$ in the extrusion direction (ED) and transverse direction (TD). 


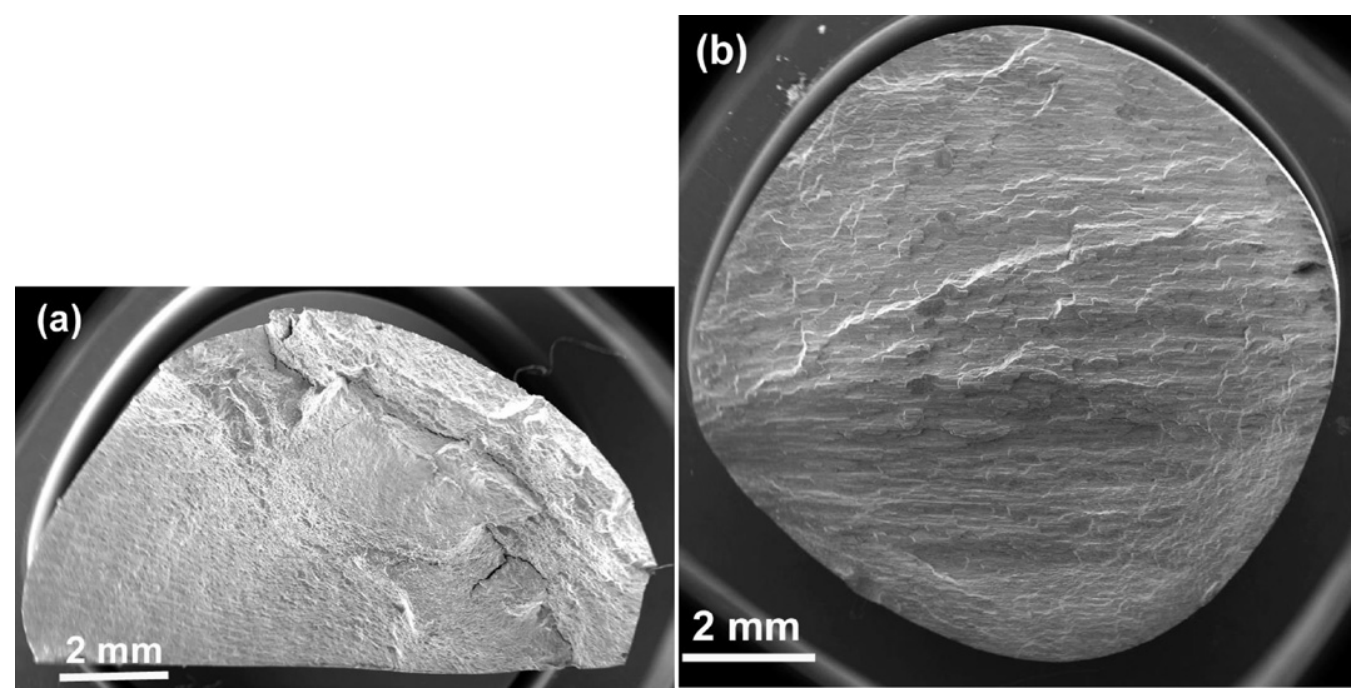

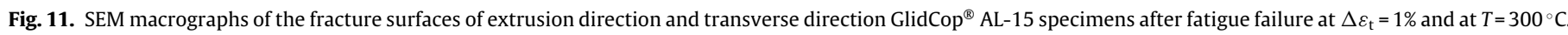

GlidCop ${ }^{\circledR}$ AL-15 exhibited higher fatigue resistance when the loading axis was parallel (extrusion direction specimens) to the direction of extrusion instead of a perpendicular loading axis (transverse direction specimen). Increasing the test temperature from $20^{\circ} \mathrm{C}$ to $300^{\circ} \mathrm{C}$ did not modify greatly the fatigue resistance of the extrusion direction specimens in contrast to the transverse direction specimens.

The total strain variation $\left(\Delta \varepsilon_{\mathrm{t}}\right)$ can be expressed as elastic strain variation $\left(\Delta \varepsilon_{\mathrm{e}}\right)$ and plastic strain variation $\left(\Delta \varepsilon_{\mathrm{p}}\right)$ :

$\Delta \varepsilon_{\mathrm{t}}=\Delta \varepsilon_{\mathrm{e}}+\Delta \varepsilon_{\mathrm{p}}$

The Manson-Coffin relation is given in the form:

$\frac{1}{2} \Delta \varepsilon_{\mathrm{p}}=\varepsilon_{\mathrm{f}}^{\prime}\left(N_{\mathrm{f}}\right)^{c}$

where $\varepsilon_{\mathrm{f}}^{\prime}$ is the fatigue ductility coefficient and $c$ is the fatigue ductility exponent. The relevant parameters obtained are summarized in Table 3.

\subsubsection{Fracture surface}

Low magnification observations of the fracture surfaces after fatigue failure at $T=300^{\circ} \mathrm{C}$ and at $\Delta \varepsilon_{\mathrm{t}}=1 \%$ are shown in Fig. 11 .

The fracture surfaces of both transverse direction and extrusion direction specimens exhibited the general features of a typical fatigue fracture. There were multiple crack initiation sites after which a major fatigue crack propagated into the bulk. The final fracture occurred during the last tension cycle when the cross section could not sustain the applied load. However, macroscopically, the cracks were different. The fracture surface of transverse direction specimen appeared rather flat and was characterized by a laminated morphology similar to that observed for the monotonic tensile fracture surface. At higher magnifications, fatigue striations homogeneously covering the surface were visible (Fig. 12). For the

\section{Table 3}

Fatigue ductility coefficient $\left(\varepsilon_{\mathrm{f}}^{\prime}\right)$ and fatigue ductility exponent $(c)$ of the Manson-Coffin relation for GlidCop ${ }^{\circledR}$ AL-15 tested at room temperature and at $300{ }^{\circ} \mathrm{C}$ in the transverse direction and extrusion direction.

\begin{tabular}{lcrl}
\hline GlidCop $^{\circledR}$ AL-15 & $T\left({ }^{\circ} \mathrm{C}\right)$ & $\varepsilon_{\mathrm{f}}^{\prime}(\%)$ & \multicolumn{1}{c}{$c$} \\
\hline Transverse direction & 20 & 174.28 & -0.97 \\
Extrusion direction & 20 & 10.75 & -0.53 \\
Transverse direction & 300 & 1.76 & -0.36 \\
Extrusion direction & 300 & 6.54 & -0.48 \\
\hline
\end{tabular}

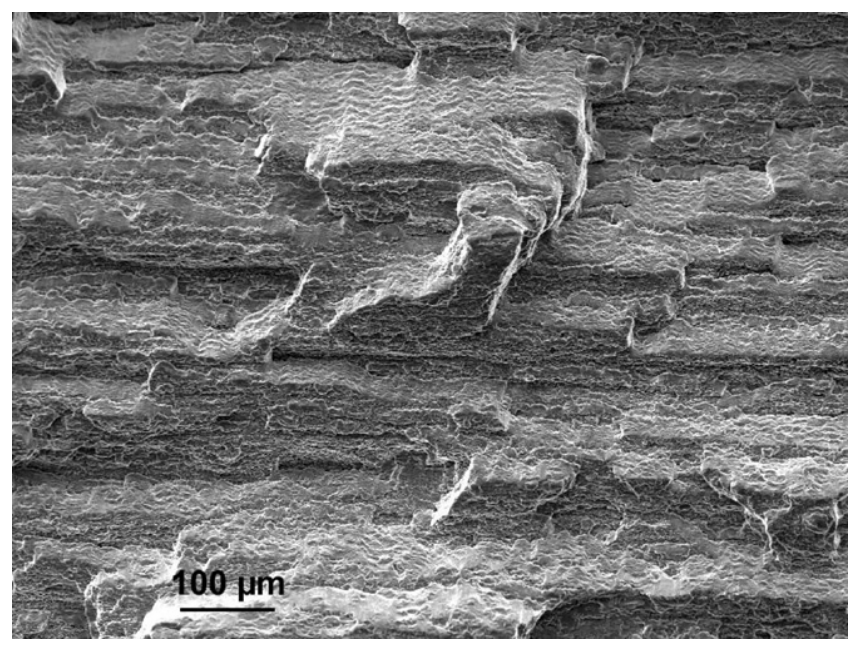

Fig. 12. SEM fractograph showing fatigue striations on the fracture surfaces of transverse direction GlidCop ${ }^{\circledR}$ AL-15 specimen after test at $\Delta \varepsilon_{\mathrm{t}}=1 \%$ and at $T=300^{\circ} \mathrm{C}$.

extrusion direction specimen, the large area corresponding to the main fatigue crack contained macroscopic beach marks at low magnification (see Fig. 11a). At higher magnification, a noticeable relief was seen consisting of raised marks separated by steep sided valleys. Both marks and valleys were covered by fatigue striations suggesting that the fatigue crack propagated through the bulk in a wavy manner.

\section{Discussion}

The present study shows that the extruded GlidCop ${ }^{\circledR}$ AL-15 rod features anisotropy resulting from the manufacturing production, and this affects the mechanical behaviour. The effect of adding $\mathrm{Al}_{2} \mathrm{O}_{3}$ nanoparticles along with the anisotropy effect results in the specific properties of GlidCop ${ }^{\circledR}$ AL-15.

In terms of mechanical strength, loading GlidCop ${ }^{\circledR}$ AL-15 at room temperature in the extrusion direction requires higher stress values (for the same strain value) than in the transverse direction, and the loading is monotonic or cyclic. It is interesting to note that the same hardening rate was measured for both extrusion and transverse directions. This suggests that plasticity should be accommodated by similar mechanisms. The Schmid factor frequency was 

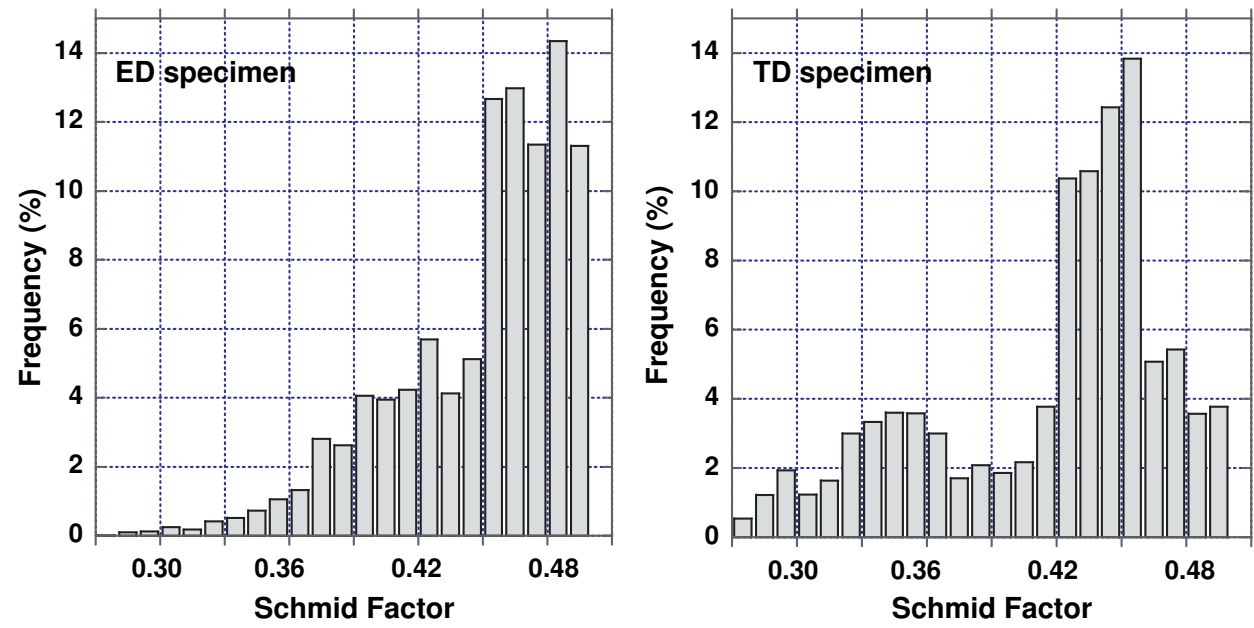

Fig. 13. Schmid factor variation on surface of extrusion direction (left) and transverse (right) direction GlidCop ${ }^{\circledR}$ AL-15 specimens.

represented on extrusion and transverse direction surfaces (Fig. 13a and $b$, respectively) by calculations based on the crystallographic orientation distribution.

As can be seen, the calculated Schmid factor values for the extrusion direction specimen are in the range of around 0.45 with a relative variation from 0.42 to 0.47 . In contrast, for the transverse specimen, two populations of values can be noted: one with a peak at 0.35 and another with a peak at 0.45 . Therefore, plastic deformation should be triggered more easily and more homogeneously in an extrusion direction-oriented GlidCop ${ }^{\circledR}$ AL-15 specimen than one oriented in a transverse direction. For the latter especially, one given population of grains is expected to accommodate plasticity with difficulty, while the other is expected to be very active.

However, when considering the morphologic texture, it turns out that the gliding path for dislocations is larger in the transverse direction-oriented specimen than in the extrusion directionoriented one. Indeed, in the former case, grains are elongated, whereas in the latter they are round. The result of hardening by grain size was effective in the extrusion direction-oriented specimen in which dislocations very frequently encounter grain boundaries acting as obstacles. In fact this last effect prevails over the orientation effect.

Orientation plays a role in the plasticity threshold at a more or less high stress value, but it affects dislocation motion only at the start of the first microvoids in the bulk sample. However, crack initiation by microvoid coalescence and crack growth from the interior to the exterior of the specimen are promoted when the material is loaded in the transverse direction. Indeed, the laminated morphology acts as a favourable path for crack advance. This also explains why necking is unfavoured in the transverse direction specimen as compared to the extrusion direction specimen.

The same explanation applies in the case of cyclic loading where plasticity occurs. The fact that a strong initial cyclic hardening occurred for the extrusion direction specimen during the test at $\Delta \varepsilon_{\mathrm{t}}=1 \%$ supports this assumption. For this condition, a multiple slip is likely to be activated from the beginning of cycling.

The presence of a more homogeneous partition of plastic deformation in the extrusion direction specimen than in the transverse direction specimen had a beneficial effect on fatigue resistance (Fig. 10). Crack initiation should proceed in the same way but it occurred earlier in the transverse direction specimen because of strain localization in the specimen.

This study shows that designers must pay attention to the selection of mechanical properties in modelling or calculating their structure.

\section{Conclusions}

The aim of the present work was to study the effect of anisotropy of oxide dispersion- strengthened (ODS) copper alloy on the mechanical properties. GlidCop ${ }^{\circledR} \mathrm{AL}-15$, a copper matrix containing $0.3 \mathrm{wt} . \%$ of $\mathrm{Al}_{2} \mathrm{O}_{3}$ provided in the form of extruded rod, was investigated. Both the monotonic tensile response and the low cycle fatigue behaviour were considered by testing the material in the extrusion direction or in the transverse direction.

The following conclusions can be drawn:

1. The extrusion process provokes both a morphologic and crystallographic texture in the GlidCop ${ }^{\circledR}$ AL-15 with grains elongated along the extrusion direction and featuring a duplex $\langle 111\rangle /\langle 100\rangle$ texture.

2. Anisotropy effects on tensile and cyclic response are clear. Higher strength values are measured for specimen loading in the extrusion direction.

3. Specimens cyclically loaded in the extrusion direction exhibit higher fatigue resistance. A factor of 10 in the fatigue lifetime is measured between transverse direction and extrusion direction specimens.

4. The plastic deformation ability is controlled by the grain morphology which provides a glide path rather than by the crystallographic texture.

5. After fracture, fractography differs between extrusion and transverse direction specimens on a macroscopic scale but not on a microscopic scale.

6. Flat surface fractures with a laminated aspect are observed for the transverse direction specimens.

7. On a microscopic scale, microvoids are observed after tensile fracture and fatigue striations after cyclic loading in both extrusion and transverse direction specimen specimens.

\section{References}

[1] T. Sunao, S. Mutsumi, T. Mochizuki, A. Watanabea, H. Kitamura, J. Synchrotron Rad. 15 (2008) 144-150.

[2] V. Ravindranath, S. Sharma, B. Rusthoven, M. Gosz, L. Zhang, J.-C. Biasci, Proceedings of the International Workshop on mechanical engineering design of Synchrotron Radiation Equipment and Instrumentation, Himeji, Hyogo, Japan, 2006.

[3] K.D. Leedy, J.F. Stubbins, B.N. Singh, F.A. Gamer, J. Nucl. Mater. 233-237 (1996) 547-552.

[4] M. Al-Hajri, A. Melendez, R. Woods, T.S. Srivatsan, J. Alloys Compd. 290 (1999) 290-297. 
[5] Jongsang Lee, Yong Chan Kim, Sunghak Lee, Sangho Ahn, Nack Kim, Metall. Mater. Trans. A 35A (2004) 493-502.

[6] M.X. Guo, M.P. Wang, L.F. Cao, R.S. Lei, Mater. Charact. 58 (2007) 928-935.

[7] J.D. Troxell, Proc. 13th Symposium on Fusion Engineering, vol. 2, 1989, pp. 761-765.

[8] S. Sato, T. Hatano, T. Kuroda, K. Furuya, S. Hara, M. Enoeda, H. Takatsu, J. Nucl. Mater. 258-263 (1998) 265-270.

[9] M.A. Morris, D.G. Morris, Mater. Sci. Eng. A 111 (1989) 115-127.

[10] J.R. Groza, J.C. Gibeling, Mater. Sci. Eng. A 171 (1993) 115-125.

[11] T. Srivatsana, N. Narendrab, J.D. Troxell, Mater. Des. 21 (2000) 191-198.

[12] F.J. Humphreys, Acta Metall. 25 (1977) 1323-1344.

[13] T. Hatano, M. Gotoh, T. Yamada, Y. Nomura, M. Saito, Fusion Eng. Des. 49-50 (2000) 207-212.
[14] S. Tahtinen, A. Laukkanen, B.N. Singh, J. Nucl. Mater. 283-287 (2000) 1028-1032.

[15] S.D. Preston, I. Bretherton, C.B.A. Forty, Fusion Eng. Des. 66-68 (2003) 441-446.

[16] L. Thomas-Ogbuji, D.L. Humphrey, Oxidation-reduction resistance of advanced copper alloys. NASA/TM.2003-212549.

[17] P. Wycliffe, Literature Search on High Conductivity Copper Based Alloys, Final Report IDWA No. 6458-2, Rockwell International Sci. Center, R5739TC/sn, 1984.

[18] D.J. Alexander, S.J. Zinkl, A.F. Rowcliffe, J. Nucl. Mater. 271-272 (1999) 429-434

[19] R. Solomon, D. Troxell, V. Nadkarni, J. Nucl. Mater. 233-237 (1996) 543-550.

[20] A.V. Nadkarni, J.D. Troxell, F. Verniers, GlidCop: dispersion strengthened copper: an advanced copper alloy system for automotive and aerospace applications; Internal Report; SCM Metal Products Inc; Cleveland, OH, USA.

[21] M. Li, J.K. Heuer, J.F. Stubbins, D.J. Edwards, J. Nucl. Mater. 283-287 (2000) 977-981. 